\title{
The impact of substituting SFA in dairy products with MUFA or PUFA on CVD risk: evidence from human intervention studies
}

\author{
Katherine M. Livingstone ${ }^{1 *}$, Julie A. Lovegrove ${ }^{2}$ and D. Ian Givens ${ }^{1}$ \\ ${ }^{1}$ Food Production and Quality Research Division, School of Agriculture, Policy and Development, Faculty of Life Sciences, \\ University of Reading, Reading RG6 GAR, UK \\ ${ }^{2}$ Department of Food and Nutritional Sciences and Institute for Cardiovascular and Metabolic Research (ICMR), School of \\ Chemistry, Food and Pharmacy, Faculty of Life Sciences, The University of Reading, Reading RG6 GAR, UK
}

(Submitted 13 February 2012 - Final revision received 12 April 2012 - Accepted 13 April 2012 - First published online 6 August 2012)

\section{Abstract}

With the substantial economic and social burden of CVD, the need to modify diet and lifestyle factors to reduce risk has become increasingly important. Milk and dairy products, being one of the main contributors to SFA intake in the UK, are a potential target for dietary SFA reduction. Supplementation of the dairy cow's diet with a source of MUFA or PUFA may have beneficial effects on consumers' CVD risk by partially replacing milk SFA, thus reducing entry of SFA into the food chain. A total of nine chronic human intervention studies have used dairy products, modified through bovine feeding, to establish their effect on CVD risk markers. Of these studies, the majority utilised modified butter as their primary test product and used changes in blood cholesterol concentrations as their main risk marker. Of the eight studies that measured blood cholesterol, four reported a significant reduction in total and LDL-cholesterol (LDL-C) following chronic consumption of modified milk and dairy products. Data from one study suggested that a significant reduction in LDL-C could be achieved in both the healthy and hypercholesterolaemic population. Thus, evidence from these studies suggests that consumption of milk and dairy products with modified fatty acid composition, compared with milk and dairy products of typical milk fat composition, may be beneficial to CVD risk in healthy and hypercholesterolaemic individuals. However, current evidence is insufficient and further work is needed to investigate the complex role of milk and cheese in CVD risk and explore the use of novel markers of CVD risk.

\section{Key words: SFA: Milk: Dairy products: CVD}

\section{Introduction}

Milk and dairy products are important sources of essential micronutrients, including $\mathrm{Ca}$, riboflavin and vitamin $\mathrm{B}_{12}$, yet being major contributors to SFA intake, have been investigated for their role in the development of chronic diseases such as CVD, obesity and the metabolic syndrome ${ }^{(1)}$. The proportion of SFA entering the food chain from milk and dairy products is typically controlled by industrial skimming, which reduces total milk fat. Alternatively, research has shown that alteration of the diet of the dairy cow, by feeding a diet high in MUFA and/or PUFA, can lead to partial replacement of milk SFA with these unsaturated fatty acids (UFA) ${ }^{(2)}$. Critically, this strategy increases proportions of potentially cardioprotective MUFA and PUFA, while simultaneously reducing proportions of SFA. The present review will examine the limited number of human dietary intervention studies that have investigated the effects of these milk and dairy products that have been modified through alteration of the dairy cow's diet on cardiovascular risk markers.

\section{Burden of CVD}

CVD, encompassing CHD, stroke and peripheral vascular diseases, is responsible for almost half of all premature deaths in Europe (Table 1$)^{(3)}$. According to the latest report by the British Heart Foundation, CVD also remains the biggest killer in the UK, responsible for one in three deaths ${ }^{(4)}$. CHD is itself the primary cause of mortality, and in 2008 accounted for one in five male and one in eight female mortalities in the UK. Evidence suggests that in Western Europe the number of mortalities from CVD is falling, whereas in Eastern Europe, mortality rates rose by as much as $7 \%$ between 1996 and $2006^{(3)}$. Estimates suggest that a total of 7.5 million individuals in the UK are living with CVD $(2 \cdot 7$ million with CHD, $2 \cdot 1$ million with angina and 1.5 million having had a myocardial infarction $)^{(4)}$. As shown in Table 1 , morbidity rates in the UK are also substantial, and have led to the UK having one of the highest expenditures on CVD in Europe (12\% of total healthcare costs, compared with the European average of $10 \%)$.

\footnotetext{
Abbreviations: FA, fatty acid; HC, hypercholesterolaemic; HDL-C, HDL-cholesterol; LDL-C, LDL-cholesterol; NC, normocholesterolaemic; RBH, ruminal
} biohydrogenation; R-TFA, ruminant trans-fatty acid; TC, total cholesterol; UFA, unsaturated fatty acid. 
Table 1. Estimated number of mortalities and cost of CHD, stroke and other vascular diseases in the UK and Europe per year $^{\star}$

\begin{tabular}{|c|c|c|c|c|c|c|}
\hline & & & \multicolumn{4}{|c|}{ Cost } \\
\hline & \multicolumn{2}{|c|}{ Mortality } & \multicolumn{2}{|c|}{ UK } & \multicolumn{2}{|c|}{ European Union } \\
\hline & UK & Europe & Direct‡ & Indirect§ & Direct & Indirect \\
\hline $\mathrm{CHD}$ & 88000 & $1.9 \mathrm{M}$ & $3.2 \mathrm{M}$ & $5 \cdot 8 \mathrm{M}$ & $23.5 \mathrm{~B}$ & $25.5 B$ \\
\hline Stroke & 43000 & $1.2 \mathrm{M}$ & $3.2 \mathrm{M}$ & $5 \cdot 1 \mathrm{M}$ & $18.6 \mathrm{~B}$ & $19 \cdot 4 \mathrm{~B}$ \\
\hline Other vascular diseases & 60000 & $1.2 \mathrm{M}$ & $8.0 \mathrm{M}$ & $5.4 \mathrm{M}$ & \multicolumn{2}{|c|}{$105 B$} \\
\hline CVD total & 191000 & $4.3 \mathrm{M}$ & \multicolumn{2}{|c|}{$30.7 \mathrm{M}$} & \multicolumn{2}{|c|}{$192 B$} \\
\hline
\end{tabular}

With the growing burden of CVD on the population and the economy, there is mounting pressure to reduce risk factors for the development of CVD. One of the main modifiable contributors to CVD risk, in addition to smoking, exercise, alcohol consumption and other dietary components, is a high consumption of saturated and trans-fat.

\section{Saturated fat consumption}

Population trends for fat consumption in the UK have changed considerably over the past century. Between 1900 and 1930, fat consumption represented $30 \%$ total energy, after which it rose to a plateau of $40 \%$ in the mid 1970 s, following a dip during the Second World War ${ }^{(5)}$. The National Diet and Nutrition Survey from 2000/01 ${ }^{(6)}$ reported that the percentage of total energy from fat was $33.5 \%$ for men and women, while the most recent results from the rolling programme for $2008 / 10^{(7)}$ suggest that UK fat consumption is close to the target (Table 2) at 33.0\% total energy for men and $34 \cdot 1 \%$ for women. With regards to SFA intake, the National Diet and Nutrition Survey reported that the proportion of energy from SFA in 2000 was $13.4 \%$ for men and $13 \cdot 2 \%$ for women, while between 2008 and 2010 this fell to $12.9 \%$ total energy for men and $12.6 \%$ for women. However, as indicated in Table 2, the proportion of energy derived from SFA is in excess of both UK and worldwide recommendations.

The potential for certain SFA to raise plasma cholesterol is well established ${ }^{(8,9)}$ and more recent evidence links SFA with the production of inflammatory markers ${ }^{(10,11)}$ and an impaired endothelial function ${ }^{(12)}$ although any link with insulin sensitivity remains uncertain ${ }^{(13,14)}$. Given these associations between dietary SFA consumption and CVD risk, this overconsumption needs to be addressed in order to combat the burden of CVD.

\section{Dairy products as a source of saturated fat}

Winter whole milk fatty acid (FA) composition (per $100 \mathrm{~g}$ FA) in the UK is typically about $72 \mathrm{~g}$ SFA, $25 \mathrm{~g}$ MUFA and
3 g PUFA (KE Kliem, personal communication); however, variation in dairy management and geographical location can have considerable effects on FA composition. For example, standard winter whole milk FA composition in the USA is $65 \mathrm{~g}$ SFA, $28 \mathrm{~g}$ MUFA and $7 \mathrm{~g}$ PUFA $^{(15)}$, while in Sweden milk FA composition is $69 \mathrm{~g}$ SFA, $28 \mathrm{~g}$ MUFA and 3 g PUFA $^{(16)}$.

Dairy products are thus a significant dietary source of SFA, estimated to contribute up to $40 \%$ of the UK SFA intake, and up to $60 \%$ in other European countries ${ }^{(17)}$. Moreover, these are likely to be underestimates, given that the contribution of milk and dairy products from composite foods was not included. The most recent data compiled on milk and dairy consumption in the UK indicates that, over the past decade, milk ingestion has declined by $15 \%$ (1766 to $1556 \mathrm{ml} /$ individual per week), while cheese and yoghurt consumption has increased by 10 and $34 \%$, respectively (103 to $111 \mathrm{~g} /$ individual per week and 149 to $202 \mathrm{ml} /$ individual per week, respectively) ${ }^{(18)}$. With an increased number of fat-reduced, and even SFA-reduced, products now on offer, it is no surprise that consumption of semiskimmed milk has increased by $0.4 \%$ year-on-year during the past decade, while the most recent data (2008-2009) for skimmed milk show a $4.3 \%$ increase in consumption ${ }^{(18)}$.

Table 2. Dietary reference values for percentage contribution of fat and fatty acids to total energy intake

\begin{tabular}{|c|c|c|c|}
\hline \multirow[b]{2}{*}{ Fat type } & \multicolumn{3}{|c|}{ Recommendations (\% energy intake) } \\
\hline & $\mathrm{SACN}^{*}$ & $\mathrm{WHO}^{(77)}$ & $\mathrm{AHA}^{(78)}$ \\
\hline Total fat & $<33$ & $20-35$ & $25-35$ \\
\hline SFA & $<10$ & 10 & $<7.0$ \\
\hline MUFA & 12 & $15-20$ & $7 \cdot 0-17$ \\
\hline Total PUFA & $6 \cdot 0-10$ & $6 \cdot 0-11$ & 10 \\
\hline \multicolumn{4}{|l|}{$n-3$ PUFA } \\
\hline Total & $>0.2$ & $0.5-2 \cdot 0$ & $1 \cdot 1-1 \cdot 6$ \\
\hline$E P A+D H A(m g / d)$ & 450 & 250 & 250 \\
\hline$n-6$ PUFA & $>1.0$ & $2 \cdot 5-9.0$ & - \\
\hline Trans & $<2 \cdot 0$ & 1.0 & $<1.0$ \\
\hline
\end{tabular}

SACN, Scientific Advisory Committee for Nutrition; AHA, American Heart Association.

*Based on data from the Department of Health ${ }^{(38)}$ 
These trends highlight the response to both government and consumer demands for products believed to be healthier.

\section{Lowering saturated fat consumption}

Despite the fat in dairy products being high in SFA, epidemiological evidence suggests that these foods may not be detrimental to cardiovascular health, although most of this evidence relates to milk $^{(19)}$. Milk and dairy products have a high $\mathrm{Ca}, \mathrm{K}$ and $\mathrm{Mg}$ content and thus have been associated with reductions in blood pressure ${ }^{(20,21)}$. Additionally, milk caseins and whey proteins (predominantly hydrolysates), sources of bioactive peptides, are becoming recognised as regulators of blood pressure in a small number of human studies ${ }^{(22)}$. Research has also suggested potential cardioprotective properties associated with conjugated linoleic acid consumption, which is unique to ruminant products ${ }^{(23)}$. Simply reducing dairy product consumption is thus not the ideal strategy to lower SFA ingestion as this may limit intake of these potentially cardioprotective agents. Instead, reducing the entry of SFA into the food chain through milk and dairy products may be achieved by altering the diet of the dairy cow to attain lower concentrations of SFA. This strategy involves partially replacing milk SFA with MUFA and/or PUFA.

\section{Replacing SFA with MUFA and/or PUFA}

Studies have shown that substituting dietary SFA with cis-MUFA and/or PUFA has beneficial effects on CVD risk factors ${ }^{(9,24)}$. Mensink et al. ${ }^{(9)}$ showed that a $1 \%$ isoenergetic replacement of carbohydrates with SFA increased LDL-cholesterol (LDL-C) by $0.032 \mathrm{mmol} / 1$, while replacement with either cis-MUFA or PUFA reduced LDL-C by 0.009 and $0.019 \mathrm{mmol} / 1$, respectively. While this metaanalysis excluded long-chain $n-3$ PUFA, the beneficial effects of these FA on CVD risk markers such as inflammation, blood pressure and vascular function are well established $^{(25)}$. A more recent systematic review and metaanalysis suggested that replacement of $9.9 \%$ of dietary energy from SFA with PUFA resulted in an overall pooled risk reduction of $19 \%$ (relative risk $0.81 ; 95 \%$ CI 0.70 , $0.95 ; P=0.008)$, corresponding to a $10 \%$ reduction in CHD risk (relative risk $0.90 ; 95 \%$ CI $0.83,0.97$ ) for each $5 \%$ energy of increased PUFA ${ }^{(26)}$. However, the basis for this evidence is limited to a small number of studies, where the total number of cardiovascular events was only 1042. Additionally, a recent symposium suggested that a replacement of $1 \%$ energy from SFA with PUFA lowered LDL-C, with a likely $2-3 \%$ reduction in incidence of $\mathrm{CHD}^{(27)}$. Nonetheless, this conclusion is based on the previously mentioned meta-analysis ${ }^{(26)}$, in addition to a study that calculated risk using a spreadsheet model that included questionable assumptions on dietary behaviour ${ }^{(28)}$.

A recent systematic review by Hooper et al. ${ }^{(24)}$ attempted to amalgamate evidence from randomised clinical trials and concluded that, based on 4586 events, reducing SFA and/or modifying dietary fat type lowered the risk of cardiovascular events by $14 \%$ (relative risk 0.86; $95 \%$ CI 0.77, 0.96). Specifically, subgrouping identified that this protective effect was only seen in studies of at least 2 years' duration (the review included studies of at least 6 months' duration), in studies of men only, and in studies where individuals had moderate to high risk of CVD at baseline. Furthermore, this review could not specify whether replacing SFA with MUFA or PUFA was more beneficial.

In excess of 100 studies $^{(29)}$ have partially replaced milk SFA with cis-MUFA and PUFA through alteration of the cow's diet. A recent study indicated that including $49 \mathrm{~g}$ rapeseed oil/kg DM in the dairy cow's diet can reduce SFA from 70 to $55-60 \mathrm{~g} / 100 \mathrm{~g}$ FA by replacing them primarily with cis-MUFA, which increased from 20 to $33 \mathrm{~g} / 100 \mathrm{~g}$ $\mathrm{FA}^{(2)}$. However, as seen in these studies, this strategy leads to the production of naturally produced ruminant trans-FA (R-TFA), which may be a concern to human health.

\section{Production of ruminant trans-fatty acids}

Comprising $65 \%$ of the total stomach capacity and playing host to a vast microbial population of ciliate protozoa, anaerobic bacteria and anaerobic fungi, the rumen is the main site of microbial fermentation and fat metabolism in the cow ${ }^{(30)}$. Rumen microbes transform dietary FA (TAG, and phospho- and galactolipids) via two processes: lipolysis and biohydrogenation. Lipolysis involves the hydrolysis of lipid ester linkages to NEFA via either plant or bacterial lipase. The latter is the process whereby UFA are first isomerised, then hydrogenated, thereby producing a number of conjugated linoleic acid isomers and trans-MUFA, also known as R-TFA ${ }^{(31)}$.

The primary ruminal biohydrogenation $(\mathrm{RBH})$ intermediate of both PUFA and MUFA is trans-11-18: 1, which, along with ruminant-produced conjugated linoleic acids, have been investigated for their beneficial effects on a variety of diseases, including cancer and $\mathrm{CVD}^{(32,33)}$. The pathways of $\mathrm{RBH}$ are complex and are dependent on the composition of the diet; for a review of RBH pathways of PUFA and MUFA, see Shingfield et al. ${ }^{(32)}$

The inclusion of UFA in the diet of the dairy cow can thus lead to increased R-TFA in the milk. Nonetheless, despite the established detrimental effects of industrially produced TFA on CVD $^{(34)}$, the impact of R-TFA is inconclusive. Some evidence has shown a protective role of R-TFA in $\mathrm{CVD}^{(35)}$, such as trans-7-16:1 ${ }^{(36)}$, while a recent review and meta-analysis by Bendsen et al. ${ }^{(37)}$ concluded that although studies to date have found a null relationship between R-TFA and CHD, the evidence from these limited studies is not sufficient to clearly identify the role of R-TFA in CVD. Importantly, it is generally accepted that this null relationship is due to a lower intake of R-TFA compared with industrial TFA. Moreover, current UK TFA consumption is $0.8 \%$ of food energy ${ }^{(7)}$, below the national 
recommended population maximum of $2 \%{ }^{(38)}$, and at this level is not considered detrimental.

\section{Scope of the review}

Modification of the dairy cow's diet to partially replace milk SFA with MUFA and/or PUFA has been extensively studied $^{(29)}$. Critically, very few human dietary intervention studies have examined the effect of these modified dairy products on CVD risk. The question of whether replacing dairy SFA with cis-MUFA or PUFA, through alteration of bovine feeding, is beneficial to cardiovascular health, is still unclear. The present review will summarise the data from the human intervention studies (Table 3) that have used milk and dairy products with modified FA composition achieved through alteration of the diet given to the cows. Two additional studies that used processing techniques to achieve these changes will not be discussed in depth in the present review ${ }^{(39,40)}$. All the studies reviewed used a supplemental source of either MUFA or PUFA in the cow diets and based the reduction in CVD risk primarily on plasma lipid concentrations. Following a critical appraisal of these studies, potential limitations and scope for future research will be highlighted.

\section{Evidence from intervention studies}

Heterogeneity of intervention studies

Of the nine studies in the present review, three supplemented the dairy cow's diet with a high proportion of MUFA $^{(41-43)}$ in order to modify milk FA composition, while three fed a source of $n-3$ PUFA $^{(44-46)}$, two fed a source of $n-6$ PUFA $^{(33,47)}$ and one failed to specify whether the 'unsaturated feed' was predominately MUFA or PUFA $^{(48)}$. Of the three studies that supplemented with a source of $n$-3 PUFA, two fed these as part of a 'livestock' $\operatorname{approach}^{(45,46)}$, which entailed also modifying the FA composition of a variety of animal products in addition to milk and dairy products. As indicated in Table 3, five of the nine studies used the modified milk to produce butter, while the remaining four produced a combination of butter and other milk and dairy products. The quality of the dietary data varies considerably, with studies omitting valuable information such as FA composition of the $\operatorname{diets}^{(43)}$, while the robustness of methods employed is equally diverse. Changes in blood cholesterol and TAG concentrations were used as the primary measure of CVD risk in all studies, except for one ${ }^{(46)}$, although the majority of these studies also measured additional risk markers including apolipoproteins, clotting factors and blood pressure.

\section{Supplementation with a source of MUFA}

The majority of the evidence in support of a beneficial impact of modified milk and dairy products on CVD risk markers results from studies where a source of MUFA was used as a feed supplement - notably rapeseed oil. Supplementation with a source of MUFA, instead of $n-3$ or $n-6$ PUFA, is seen as the more sustainable option, with comparably less lipid peroxidation and RBH. Poppitt et al $^{(48)}$ used butter-fat that had been modified by feeding an encapsulated UFA, and measured its effects on total cholesterol (TC), LDL-C and HDL-cholesterol (HDL-C), TAG, apoA and B, NEFA, haemostatic clotting factor VII, fibrinogen and glucose. This was a double-blinded, randomised, cross-over, intervention trial where volunteers were fed either a 'control' or 'modified' butter. Through feeding alone, the SFA content of the modified butter was reduced by $16 \cdot 1 \%(70 \cdot 5-54 \cdot 4 \mathrm{~g} / 100 \mathrm{~g}$ FA) and the MUFA and PUFA content was increased by $9 \cdot 9 \%(22 \cdot 1-32 \cdot 0 \mathrm{~g} / 100 \mathrm{~g} \mathrm{FA})$ and $7.5 \%(3 \cdot 0-10 \cdot 5 \mathrm{~g} / 100 \mathrm{~g}$ FA), respectively (Table 4$)$.

As expected when feeding a highly unsaturated diet, the authors reported an increase in trans-MUFA following modification of the bovine feeding regimen $(9.3 \%$ increase from 4.3 to $4.7 \mathrm{~g} / 100 \mathrm{~g} \mathrm{FA}$ ). The bovine feeding regimen utilised in this study involved encapsulation protection technology - designed to protect from RBH - although the increases in trans-MUFA indicate incomplete protection.

Poppitt et al. ${ }^{(48)}$ reported reductions in TC $(P<0.05)$ and LDL-C $(P<0 \cdot 01)$ after consuming the modified butter-fat compared with the control butter. TC and LDL-C decreased by $0.36 \mathrm{mmol} / 1 \quad(P<0.001)$ and $0.28 \mathrm{mmol} / 1 \quad(P<0.01)$, respectively, and when calculated as percentage change from baseline, by day 22 TC and LDL-C had decreased by 7.9 and $9.5 \%$, respectively. By using criteria set by the Cholesterol Treatment Trialists' meta-analysis ${ }^{(49)}$, these reductions in LDL-C would be equivalent to an approximate reduction in absolute risk of CHD and stroke of 7 and 5\%, respectively. No significant changes were reported from any of the haemostatic clotting factors, apoA and B, NEFA or serum glucose. Furthermore, no significant changes in HDL-C were observed.

Tholstrup et al. ${ }^{(42)}$ produced a modified butter by feeding a basal diet (beetroots, grass silage, crushed barley and straw) supplemented with a bovine concentrate mix of $50 \%$ soyabean meal and $50 \%$ crushed rapeseed fed at $3 \cdot 2 \mathrm{~kg} / \mathrm{cow}$ per $\mathrm{d}$. This dietary change decreased butter fat SFA concentrations from 73.7 to $56.4 \mathrm{~g} / 100 \mathrm{~g}$ FA (Table 4).

Based on results from the eighteen subjects fed an isoenergetic saturate-replacement diet in an 8-week randomised cross-over study, Tholstrup et al. ${ }^{(42)}$ concluded that feeding subjects dairy products where SFA were substituted for UFA did not lower TC or LDL-C and did not change HDL-C. A potential explanation for the lack of change in cholesterol levels may be due to the 5 -fold increase in the reported trans-18:1 seen in the modified fat compared with the control $(6.4 v \cdot 1 \cdot 1 \mathrm{~g} / 100 \mathrm{~g}$ FA). However, having the smallest sample size of all the reviewed studies, the study population may also have been a limitation.

A further two intervention studies, by Noakes et al. . $^{(1)}$ and Seidel et $a l .{ }^{(43)}$, investigated the effect of a variety 
Table 3. Summary of randomised controlled trials investigating the impact of modified milk and dairy products in which SFA were partially replaced with MUFA and/or PUFA, by supplemental bovine feeding, on CVD markers

\begin{tabular}{|c|c|c|c|c|c|c|c|c|}
\hline \multirow[b]{2}{*}{ Reference } & \multirow{2}{*}{$\begin{array}{l}\text { Experimental design } \\
\text { (n, age, study, dairy products, modified feed) }\end{array}$} & \multirow[b]{2}{*}{ Diet } & \multicolumn{5}{|c|}{ Experimental diet (\% energy intake) ${ }^{\star}$} & \multirow[b]{2}{*}{ Primary outcomes $†$} \\
\hline & & & Fat & SFA & MUFA & PUFA & UNID & \\
\hline \multirow{2}{*}{$\begin{array}{l}\text { Noakes et al. } \\
\quad(1996)^{(41)}\end{array}$} & $n$ 33, 49 years, 8-week cross-over; 2-week low-fat, 3-week & $\mathrm{C}$ & $36 \cdot 6$ & $18 \cdot 2$ & $9 \cdot 10$ & $2 \cdot 60$ & 6.70 & \multirow{2}{*}{$\begin{array}{l}\text { TC } \downarrow 4.3 \%(0.28 \mathrm{mmol} / / ; P<0.001) \text { and LDL-C } \downarrow 5.3 \% \\
\text { on } \mathrm{M}(0.24 \mathrm{mmol} / / ; P<0.001) \text { relative to C. } \leftrightarrow \mathrm{TAG} \text { or } \\
\text { HDL-C }\end{array}$} \\
\hline & $\begin{array}{l}\mathrm{C} / \mathrm{M} ;<\text { roughage; butter, milk, cheese, ice cream; } \\
\text { protected rapeseed/soyabean }\end{array}$ & M & $36 \cdot 9$ & $16 \cdot 0$ & 11.9 & $4 \cdot 20$ & $4 \cdot 80$ & \\
\hline \multirow{2}{*}{$\begin{array}{l}\text { Tholstrup et al. } \\
\qquad(1998)^{(42)}\end{array}$} & $n$ 18, 21-28 years, 16 -week cross-over; 4-week C, & C & 41.5 & $27 \cdot 1$ & 8.60 & $5 \cdot 80$ & 0.00 & \multirow{2}{*}{$\begin{array}{l}\text { TC } \uparrow 5 \%(0.23 \mathrm{mmol} / / ; P=0.006) \text { on } \mathrm{M} \text { relative to base- } \\
\text { line, TAG } \uparrow 14 \%(0.14 \mathrm{mmol} / / ; P<0.008) \text { on } \mathrm{M} \text { relative } \\
\text { to C. } \leftrightarrow \mathrm{TC}, \mathrm{LDL}-\mathrm{C} \text { or } \mathrm{HDL}-\mathrm{C} \text { between } \mathrm{C} \text { and } \mathrm{M}\end{array}$} \\
\hline & $\begin{array}{l}\text { 4-week M, 8-week washout; butter; 50:50 soyabean: } \\
\text { crushed rapeseed }\end{array}$ & M & $40 \cdot 5$ & $21 \cdot 2$ & $14 \cdot 60$ & $5 \cdot 00$ & 0.00 & \\
\hline \multirow{2}{*}{$\begin{array}{l}\text { Poppitt et al. } \\
\qquad(2002)^{(48)}\end{array}$} & n 20, NA, 10-week double-blinded, cross-over; 3-week C, & $\mathrm{C}$ & $40 \cdot 0$ & $20 \cdot 0$ & $6 \cdot 00$ & $14 \cdot 0$ & 0.00 & \multirow{2}{*}{$\begin{array}{l}\text { TC } \downarrow 7.9 \%(0.36 \mathrm{mmol} / \mathrm{l}) \text { and } \mathrm{LDL}-\mathrm{C} \downarrow 9.5 \%(0.28 \mathrm{mmol} / \mathrm{l} ; \\
P<0.01) \text { on } \mathrm{M} \text { relative to } \mathrm{C} . \leftrightarrow \mathrm{TAG} \text { or } \mathrm{HDL}-\mathrm{C} \text {, apoA } \\
\text { or B, NEFA, haemostatic clotting factor VII, fibrinogen or } \\
\text { glucose }\end{array}$} \\
\hline & $\begin{array}{l}\text { 3-week M, 4-week washout; butter; unspecified } \\
\text { 'unsaturated' feed }\end{array}$ & M & $39 \cdot 0$ & $15 \cdot 0$ & 8.00 & $16 \cdot 0$ & 0.00 & \\
\hline \multirow{2}{*}{$\begin{array}{l}\text { Seidel et al. } \\
\quad(2005)^{(43)}\end{array}$} & $n 31,16-66$ years, $13-$ week; $7 \mathrm{~d}$ habitual diet, $10 \mathrm{~d}$ low-fat, & C-B & $37 \cdot 2$ & $26 \cdot 3$ & $9 \cdot 50$ & $1 \cdot 10$ & 0.30 & \multirow[b]{2}{*}{ 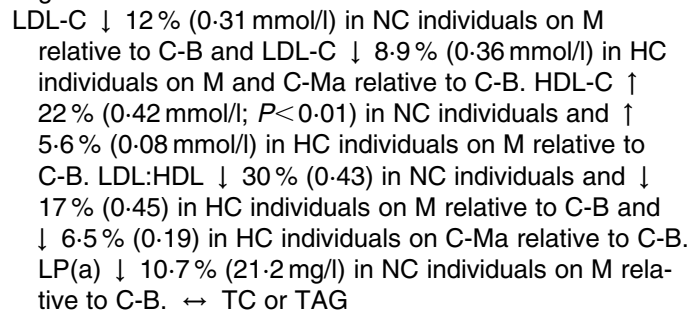 } \\
\hline & $\begin{array}{l}18 \mathrm{~d}(\mathrm{C}-\mathrm{B}), 10 \mathrm{~d} \text { low-fat, } 18 \mathrm{~d} \mathrm{M}, 10 \mathrm{~d} \text { low-fat, } 18 \mathrm{~d} \\
\text { (C-Ma); butter, milk, yoghurt; rapeseed cake }\end{array}$ & M & $36 \cdot 7$ & $22 \cdot 9$ & $12 \cdot 2$ & $1 \cdot 30$ & 0.30 & \\
\hline \multirow{2}{*}{$\begin{array}{l}\text { Tholstrup et al. } \\
\qquad(2006)^{(33)}\end{array}$} & $n$ 42, 19-33 years, 5-week double-blind, parallel; C or M & C & $42 \cdot 0$ & $24 \cdot 4$ & $9 \cdot 60$ & $3 \cdot 60$ & 4.40 & \multirow[b]{2}{*}{$\begin{array}{l}\mathrm{HDL}-\mathrm{C} \downarrow 9 \%(0.15 \mathrm{mmol} / \mathrm{l} ; P=0.002) \text { and TC } \downarrow 6 \% \\
(0.3 \mathrm{mmol} / \mathrm{l} ; P=0.05) \text { on } \mathrm{M} \text { relative to } \mathrm{C} . \leftrightarrow \mathrm{LDL} \\
(P=0.14), \mathrm{TAG}(P=0.30), \text { Ur.8-iso-PGF }(P=0.95), \\
\mathrm{CRP}(P=0.67), \text { haemostatic clotting factor VIlc } \\
(P=0.29), \mathrm{PAl}-1(P=0.21), \text { insulin }(P=0.14) \text { or } \\
\text { glucose }(P=0.21)\end{array}$} \\
\hline & (vaccenic acid-rich); butter; sunflower seeds & M & $44 \cdot 6$ & $22 \cdot 5$ & 14.9 & $3 \cdot 80$ & 3.40 & \\
\hline \multirow{2}{*}{$\begin{array}{l}\text { Lacroix et al. } \\
\qquad(2012)^{(47)}\end{array}$} & $n$ 72, 18-70 years, 8-week double-blind, randomised, & $\mathrm{C}$ & 33 & 9.90 & $14 \cdot 7$ & $5 \cdot 90$ & 2.50 & \multirow{2}{*}{$\begin{array}{l}\text { HDL-C } \downarrow 3 \%(0.05 \mathrm{mmol} / / ; P=0.004) . \leftrightarrow \text { TC }(P=0.32), \\
\text { LDL }(P=0.77), \mathrm{TAG}(P=0.99), \text { apoB }(P=0.83), \text { apoA-1 } \\
(P=0.09), \text { systolic blood pressure }(P=0.31) \text {, diastolic } \\
\text { blood pressure }(P=0.44)\end{array}$} \\
\hline & cross-over, $3 \mathrm{~d}$ washout; butter; maize oil & M & 33 & $10 \cdot 3$ & 14.4 & 5.90 & $2 \cdot 40$ & \\
\hline \multirow{3}{*}{$\begin{array}{l}\text { Malpuech-Brugère } \\
\text { et al. }(2010)^{(44)}\end{array}$} & $n 111,18-50$ years, 4-week double-blind, randomised, & LO & $37 \cdot 7$ & 21.5 & 11.4 & 3.60 & 1.00 & \multirow{3}{*}{$\begin{array}{l}\text { LDL-C } \downarrow 6 \%(0.14 \mathrm{mmol} / / ; P=0.04) \text { and TC } \downarrow 3 \% \\
\quad(0.13 \mathrm{mmol} / / ; P=0.04) \text { on } \mathrm{L} 4 \text { relative to L0. } \leftrightarrow \mathrm{HDL}\end{array}$} \\
\hline & parallel; $72 \%$ SFA, $2.85 \%$ R-TFA (L0), $63.3 \%$ SFA, & L4 & $39 \cdot 2$ & $22 \cdot 1$ & $11 \cdot 7$ & 3.50 & 1.90 & \\
\hline & $4.06 \%$ R-TFA (L4), $56.6 \%$ SFA, $12.16 \%$ R-TFA (L9); & L9 & $38 \cdot 8$ & $22 \cdot 6$ & 11.9 & $3 \cdot 60$ & 0.70 & \\
\hline
\end{tabular}




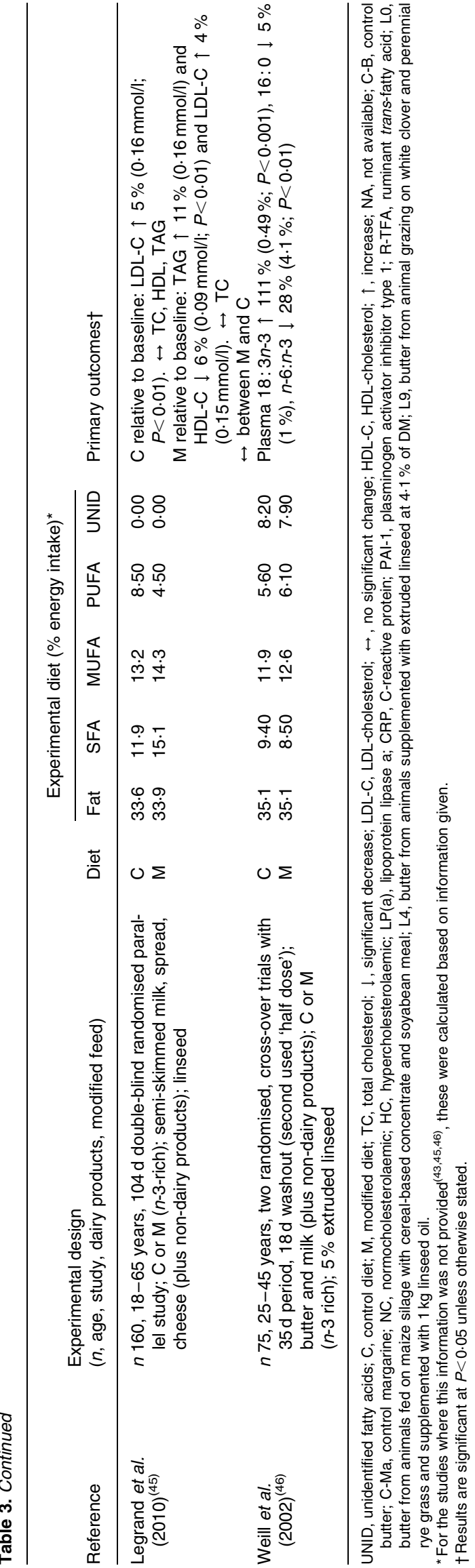

of dairy products on blood biomarkers. Noakes et al. ${ }^{(41)}$ provided a low-roughage diet to reduce ruminal acetate production. Acetate, being a precursor of endogenous (de novo) short- and medium-chain FA synthesis in the mammary gland, is reduced by a low-roughage diet, which in turn is generally believed to limit SCFA synthesis (predominantly SFA). Furthermore, a protein-encapsulated lipid (rapeseed and soyabean oil) provided a source of PUFA that was partially protected from RBH.

Noakes et al. ${ }^{(41)}$ provided modified milk, cheese, butter and ice cream with a SFA:MUFA:PUFA proportion of 51:39:10, compared with control products with the composition of 70:28:2 (Table 4). A detailed FA composition of diets was not provided, although R-TFA were estimated at 2.2 and $3.4 \mathrm{~g} / 100 \mathrm{~g}$ FA for the fat-modified and conventional milk, respectively. After conducting an 8-week, randomised, cross-over study in thirty-three men and women, the modified dairy products reduced TC $(-0.28 \mathrm{mmol} / \mathrm{l}$; $P<0.001)$ and LDL-C $(-0.24 \mathrm{mmol} / 1 ; P<0.001)$ although there was no change in HDL-C. In comparison with the previous study by Tholstrup et al. ${ }^{(42)}$, FA compositional data were limited and no additional markers of CVD risk were measured other than plasma cholesterol.

Seidel et al. ${ }^{(43)}$ fed a diet of MUFA-rich rapeseed cake to achieve changes in milk FA concentrations, which was used to produce butter and yoghurt. As part of a 13-week, three-phase, randomised, cross-over, controlled study, subjects were fed modified milk, butter and yoghurt, nonmodified milk, butter and yoghurt, as well as non-modified milk, margarine and yoghurt. As summarised in Table 3, results indicated that LDL-C was reduced $(-0.32 \mathrm{mmol} / \mathrm{l}$; $P<0.05)$ when the modified products were consumed, while HDL-C was increased $(+0 \cdot 23 \mathrm{mmol} / 1 ; P<0 \cdot 05)$, resulting in a reduced LDL:HDL ratio $(-0 \cdot 38 ; P<0 \cdot 05)$. This study was the only one to compare the effects of modified dairy products between normocholesterolaemic (NC) subjects and hypercholesterolaemic (HC) subjects. Results showed that dairy products with low SFA and high MUFA/PUFA concentrations increased HDL-C $(+0.42 \mathrm{mmol} / 1 ; P<0 \cdot 01)$ in NC subjects. Given that $\mathrm{HC}$ subjects tend to have greater reductions in cholesterol than healthy individuals ${ }^{(50)}$, these results were unexpected. However, the imbalance in subject group sizes (nine HC and twenty-two NC subjects) is likely to have affected the results. Nonetheless, of all the studies reviewed, that of Seidel et al. ${ }^{(43)}$ was the only one to show a beneficial change in HDL-C levels (Table 3) when lowSFA-content dairy products were consumed. Moreover, this study achieved the most substantial changes in serum cholesterol fractions with the smallest difference between the percentage SFA of the modified and control milk and dairy products (Fig. 1). A potential explanation may be the minimal confounding effect from R-TFA content, although this could not be confirmed due to limited FA compositional data. 
Table 4. Comparison of fatty acid (FA) profiles of test products and test diets

\begin{tabular}{|c|c|c|c|c|c|c|c|c|}
\hline \multirow[b]{2}{*}{ Reference } & \multirow[b]{2}{*}{ Diet } & \multicolumn{4}{|c|}{$\begin{array}{l}\text { FA profile of test products } \\
\qquad(\mathrm{g} / 100 \mathrm{~g} \mathrm{FA})\end{array}$} & \multicolumn{3}{|c|}{$\begin{array}{l}\text { FA profile of diets } \\
(\mathrm{g} / 100 \mathrm{~g} \mathrm{FA})^{\star}\end{array}$} \\
\hline & & SFA & MUFA & PUFA & UNID & SFA & MUFA & PUFA \\
\hline \multirow[t]{2}{*}{ Noakes et al. (1996) } & $\mathrm{C}$ & $70 \cdot 0$ & $28 \cdot 0$ & 2.00 & 0.00 & 59.9 & $31 \cdot 2$ & 8.90 \\
\hline & $M$ & 51.0 & 39.0 & 10.0 & 0.00 & 49.8 & 37.1 & 13.1 \\
\hline \multirow{2}{*}{ Tholstrup et al. $(1998)^{(42)}$} & C & $73 \cdot 7$ & $20 \cdot 6$ & 2.55 & 4.76 & 65.3 & $20 \cdot 8$ & 14.0 \\
\hline & $M$ & $56 \cdot 4$ & $36 \cdot 8$ & 4.00 & 4.78 & 51.9 & $35 \cdot 8$ & $12 \cdot 3$ \\
\hline \multirow{2}{*}{ Poppitt et al. (2002) $)^{(48)}$} & $\mathrm{C}$ & 70.5 & $22 \cdot 1$ & 3.00 & 4.40 & $50 \cdot 0$ & $15 \cdot 0$ & $35 \cdot 0$ \\
\hline & $M$ & 54.4 & $32 \cdot 0$ & 10.5 & $3 \cdot 10$ & 38.4 & 20.5 & 41.0 \\
\hline \multirow[t]{2}{*}{ Seidel et al. $(2005)^{(43)}$} & $\mathrm{C}$ & $70 \cdot 8$ & 25.5 & 3.02 & 0.68 & $70 \cdot 8$ & 25.5 & 3.02 \\
\hline & $M$ & $62 \cdot 6$ & 33.3 & 3.63 & 0.49 & $62 \cdot 6$ & 33.3 & 3.63 \\
\hline \multirow[t]{2}{*}{ Tholstrup et al. $(2006)^{(33)}$} & $\mathrm{C}$ & 60.5 & $12 \cdot 3$ & 1.50 & $25 \cdot 7$ & $64 \cdot 9$ & $25 \cdot 5$ & 9.60 \\
\hline & $M$ & $46 \cdot 7$ & 28.4 & 3.00 & 21.9 & $54 \cdot 7$ & $36 \cdot 2$ & 9.20 \\
\hline \multirow[t]{2}{*}{ Lacroix et al. (2012) $)^{(47)}$} & $\mathrm{C}$ & $68 \cdot 4$ & $27 \cdot 1$ & 3.60 & 0.90 & $32 \cdot 4$ & $48 \cdot 2$ & $19 \cdot 3$ \\
\hline & $M$ & $54 \cdot 2$ & 39.6 & 3.80 & 0.90 & 33.7 & $47 \cdot 1$ & $19 \cdot 3$ \\
\hline \multirow[t]{3}{*}{ Malpuech-Brugère et al. (2010) ${ }^{(44)}$} & LO & $72 \cdot 0$ & 22.4 & 5.66 & 0.00 & 58.0 & $32 \cdot 2$ & 9.81 \\
\hline & L4 & $63 \cdot 3$ & $29 \cdot 7$ & 6.97 & 0.00 & $52 \cdot 7$ & $37 \cdot 0$ & $10 \cdot 3$ \\
\hline & L9 & $56 \cdot 6$ & 33.2 & 10.3 & 0.00 & 48.1 & 38.0 & $13 \cdot 8$ \\
\hline \multirow[t]{2}{*}{ Legrand et al. $(2010)^{(45)}$} & $\mathrm{C}$ & $53 \cdot 6$ & $17 \cdot 4$ & 2.00 & $27 \cdot 0$ & 35.5 & $39 \cdot 3$ & $25 \cdot 2$ \\
\hline & $M$ & 47.4 & 20.4 & 3.20 & 29.0 & 44.6 & $42 \cdot 1$ & $13 \cdot 2$ \\
\hline \multirow[t]{2}{*}{ Weill et al. (2002) ${ }^{(46)}$} & $\mathrm{C}$ & $43 \cdot 0$ & $20 \cdot 0$ & $3 \cdot 10$ & 33.9 & 34.4 & 43.5 & 21.9 \\
\hline & M & $37 \cdot 0$ & $26 \cdot 0$ & 5.40 & 31.6 & 31.5 & $46 \cdot 8$ & 21.9 \\
\hline
\end{tabular}

\section{Supplementation with a source of n-6 PUFA}

Of the studies reviewed, two were specifically designed to increase concentrations of R-TFA, predominantly $18: 1 n-7$, in butter and investigate the effects of this modified product on CVD risk markers ${ }^{(33,47)}$. While Tholstrup et $a l .{ }^{(33)}$ introduced sunflower seeds to the cow's diet (undeclared inclusion rate) and increased total trans-18:1 from $0 \cdot 4 \mathrm{~g} / 100 \mathrm{~g}$ FA in the control butter to $5 \cdot 0 \mathrm{~g} / 100 \mathrm{~g}$ in the modified butter, Lacroix et al. ${ }^{(47)}$ fed a mixed diet of concentrates, lucerne and maize silage, with the addition of $3.6 \%$ maize oil and increased total trans-18:1 from $4 \cdot 1 \mathrm{~g} / 100 \mathrm{~g}$ FA in the control butter to $12.4 \mathrm{~g} / 100 \mathrm{~g}$ in the modified butter. This was equivalent to $3 \mathrm{~g}$ R-TFA/d ( $1.2 \%$ energy intake) in that of Lacroix et al. ${ }^{(47)}$, and in excess of $3.6 \mathrm{~g} / \mathrm{d}(1.4 \%$ energy intake) in that of Tholstrup et $a l .{ }^{(33)}$. Both are above the average UK intake of R-TFA ${ }^{(7)}$.

Although both studies considerably increased concentrations of R-TFA in the modified butter products, and saw large differences in concentrations of SFA and PUFA between the modified and control butters (Table 4), they differed in diet design strategies. Critically, Tholstrup et $a l .{ }^{(33)}$ did not match percentage energy from SFA, MUFA and PUFA between the control and modified diets and subsequently showed a $5.9 \%$ difference in percentage of energy from SFA, whereas Lacroix et al. ${ }^{(47)}$ sought to match the percentage energy intakes between diets, with a comparable exchange of cis-18:1 for trans-18:1 in the modified diet, seeing a negligible $0 \cdot 4 \%$ difference in percentage energy from SFA between diets.
Tholstrup et al. ${ }^{(33)}$ reported reductions in TC $(-6 \%$; $-0.03 \mathrm{mmol} / \mathrm{l} ; P=0.05)$ and HDL-C $(-9 \% ;-0.27 \mathrm{mmol} / 1$; $P=0.002$ ), yet noted that the increase in MUFA and reduction in SFA were likely to be responsible for this rather than the R-TFA. In contrast, Lacroix et al. ${ }^{(47)}$ saw no significant change in TC, yet did see a significant decline in HDL-C $(-3 \% ;-0.05 \mathrm{mmol} / \mathrm{l} ; P=0.004)$. The author attributes the lack of beneficial changes in cholesterol and other markers of CVD to the study population characteristics; notably the inclusion of only healthy women, for which there is limited information.

\section{Supplementation with a source of n-3 PUFA}

While the majority of evidence for the beneficial effect of modified milk and dairy products originates from studies where bovine diets were fed with a high proportion of MUFA, a small number of studies have looked specifically at $n$-3 PUFA products and will be reviewed subsequently. However, it is worthy of note that two of these studies adopted a 'livestock' approach, thereby modifying not only milk and dairy product FA composition but also that of other animal products, such as eggs, pork and chicken $^{(44,45)}$. Subsequently, it was not possible to differentiate the effect of consumption of modified milk and dairy products from that of other modified animal products. The source of $n$-3 PUFA in the following studies was plant oils. Although supplementation with marine oils is an option, it can adversely affect rumen function ${ }^{(51)}$. An important plant source of $n-3 \mathrm{FA}$, linseed, is a more economical 
(a)

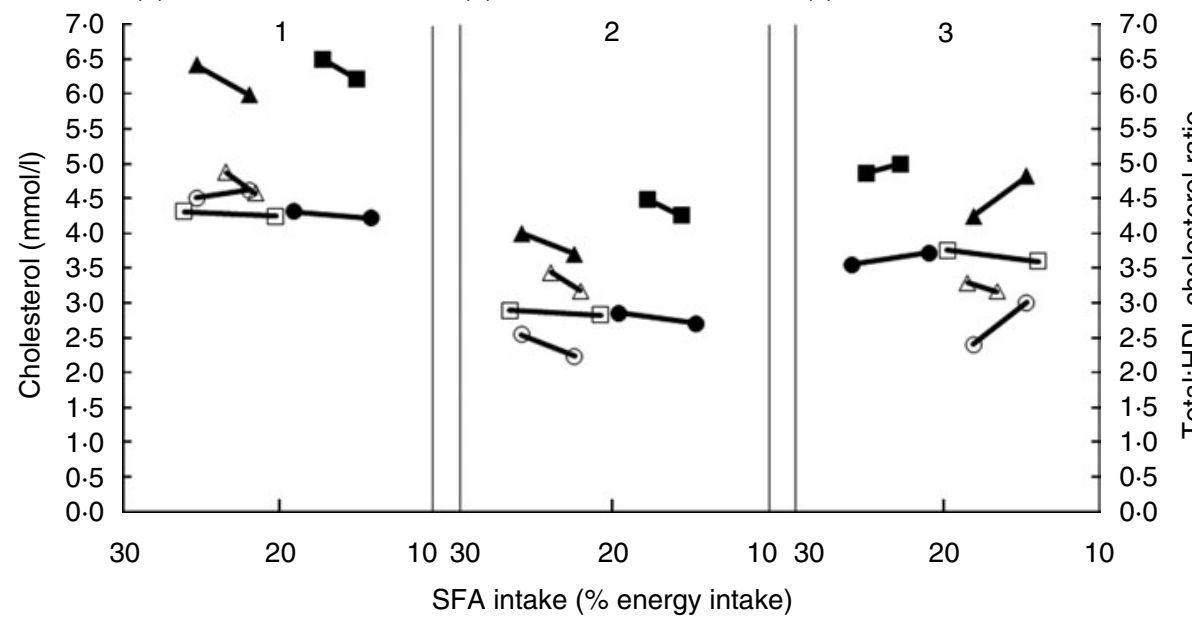

Fig. 1. Effect of decreasing the percentage energy from milk fat SFA concentrations on total cholesterol concentration (a), LDL-cholesterol concentration (b) and

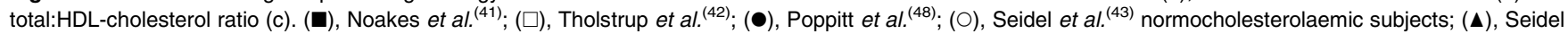
et al. ${ }^{(43)}$ hypercholesterolaemic subjects; $(\triangle)$, Tholstrup et al. ${ }^{(33)}$. Cholesterol was measured in plasma with the exception of two studies ${ }^{(43,48)}$, where this was measured in serum.

and sustainable option and has been investigated in these studies for any beneficial effects on milk FA composition and CVD risk markers.

One of the first studies to look at the link between linseed-enriched bovine diets and human serum FA concentrations was Weill et al. ${ }^{(46)}$. They conducted a 'livestock' approach by introducing varying amounts of extruded linseed supplement to modify the animal products from dairy cows (5\%), laying hens (10\%), pigs (2.5\%) and broiler chickens (3.5\%). For the duration of this study volunteers were not permitted to consume any fish or any products high in linseed or $n-3$. This study used human serum FA composition as a marker of CVD risk, although this can prove inconclusive due to further metabolism of FA after leaving the plasma ${ }^{(52)}$. Nonetheless, this study showed a substantial increase in $18: 3 n-3(+119 \%)$ in the modified dairy products and a corresponding decrease in 16:0 $(-24 \%)$. These modified dairy products successfully increased serum $18: 3 n-3$ by $111 \%(P<0 \cdot 001)$, and resulted in a 5\% decrease in 16:0 $(P<0.05)$ and a $28 \%$ reduction in the $n-6: n-3$ ratio $(P<0 \cdot 01)$. These differences proved surprising, as estimations of SFA, MUFA and PUFA intake as percentage of total energy intake suggested very little difference between the test and control periods (Table 3).

Weill et $a l^{(46)}$ failed to show an increase in the longchain n-3 PUFA $20: 5 n-3$ and $22: 6 n-3(P>0.05)$ in the modified dairy products. Furthermore, it is questionable whether the $111 \%$ increase in serum $18: 3 n-3(0.44$ to $0.93 \mathrm{~g} / 100 \mathrm{~g}$ ) seen in the subjects that consumed the modified milk and dairy products would afford health benefits. Although $18: 3 n-3$ is a precursor for endogenous synthesis of $20: 5$ and $22: 6 n-3$, in human tissue the conversion is very inefficient ${ }^{(53)}$. Therefore, the significant increase in serum concentrations of $20: 5 n-3(P<0.05)$ seen in the study subjects is likely to be attributable mainly to the consumption of the $n$-3-enriched animal products (egg, pork and chicken), which doubled in 20:5n-3 (1.2 to $2 \cdot 4 \mathrm{~g} / 100 \mathrm{~g} \mathrm{FA}$ ) following linseed feeding.

In a randomised, double-blinded trial, Legrand et al. ${ }^{(45)}$ provided a variety of modified animal products to 160 overweight volunteers over a $90 \mathrm{~d}$ period. In addition to a number of anthropometric measurements, plasma lipids (FA composition, cholesterol and TAG) were measured. The experimental animal products were of a similar nature to the previously mentioned study by Weill et $a l^{(46)}$ in that the bovine diet was supplemented with extruded linseed. While there was no significant change in erythrocyte SFA or $n$-3 PUFA concentrations between the control and the experimental group, there was an increase in erythrocyte MUFA $(5 \% ; P>0.01)$ and a decrease in erythrocyte $n-6$ PUFA concentration $(-10 \% ; P>0.001)$ in the experimental group compared with the control group (inter-group). Although there were no inter-group differences in total $n-3$ plasma FA content $(18: 3 n-3,20: 5 n-3$ and $22: 6 n-3)$, there was a lower total $n-3$ content in the control group ( $-13 \%$; $P>0.001)$ relative to their baseline measurements and an increase in the experimental group $(+13 \% ; P>0.01)$ relative to their group baseline measures (intra-group). As fish consumption was prohibited during this study, it was suggested that the animal products provided EPA and DHA, despite a low dietary intake, due to synthesis from $18: 3 n-3$ precursors.

Despite the favourable MUFA and PUFA plasma concentrations of the subjects, Legrand et al. ${ }^{(45)}$ observed no significant differences in plasma cholesterol between the experimental and the control groups (see Table 3 for significant intra-group changes in cholesterol from baseline). Nonetheless, there was a numerical increase in TC, HDL-C, LDL-C and TAG reported in the experimental group. As previously mentioned, no significant changes 
in erythrocyte SFA concentrations in the experimental group were observed, despite a numerical difference, and a $9 \%$ greater SFA content in the experimental diet compared with the control ( $2.6 \%$ difference in energy from SFA), which may account for the lack of change in plasma lipids. Moreover, the low $n-6$ PUFA in the experimental diet, subsequent erythrocyte $n$ - 6 PUFA levels and impact of potentially atherogenic R-TFA ${ }^{(37)}$ may also be responsible for these non-significant results (although R-TFA were not reported and so their impact on CVD risk markers cannot be ascertained).

Of the three linseed studies reviewed, the study by Malpuech-Brugère et $a l^{(44)}$ reported the most beneficial effect on CVD risk factors. This was a single-centre, randomised, double-blind, parallel-intervention, 4-week controlled study where cows were fed either no linseed (L0), extruded linseed (L4; $4.1 \%$ of DM), or linseed oil (L9; $1 \mathrm{~kg}$ ). Based on consumption of modified milk, double cream and cookies, LDL-C decreased by $6 \%$ $(-0.14 \mathrm{mmol} / 1 ; P=0.04)$ and TC by $3 \%(-0.13 \mathrm{mmol} / \mathrm{l}$; $P=0.04)$ on the products made from the extruded linseed diet relative to the control. The high inclusion level of linseed oil in L9 resulted in no changes in plasma lipids despite having the lowest SFA content compared with L0 and L4 (56.6 v. 63.3 and $72 \%$, respectively). This lack of beneficial effect was possibly due to the high R-TFA concentrations $(12 \cdot 16 \mathrm{~g} / 100 \mathrm{~g}$ FA). Furthermore, a $1 \mathrm{~kg}$ inclusion level of linseed oil may have negative effects on DM intake and milk yield due to disruption of rumen function ${ }^{(54)}$.

\section{Discussion}

The studies included in the present review were specifically those that tested the effects of milk and dairy products that had been modified through alteration of the cow's diet. However, as summarised in Table 3, the methodologies utilised differed considerably, notably the choice of fat supplement in the dairy cow diet, choice of milk or dairy product tested, number of subjects and study design. For example, while Tholstrup et al. ${ }^{(33)}$ conducted a 16-week cross-over study where a total of eighteen men (aged 21-28 years) were fed a butter that had been produced from a bovine diet of soyabean and crushed rapeseed, Legrand et al. ${ }^{(45)}$ ran a 15-week parallel study in 106 overweight men and postmenopausal women (aged 18-65 years) where butter was produced from a bovine diet high in linseed. Such vast shifts in focus provide insight into a range of cause-and-effect scenarios, and it is understandable that not all studies can be directly comparable. However, there is a distinct lack of quality information provided in these papers.

This lack of information is clearly illustrated by Poppitt et $a l .{ }^{(48)}$, where there was a failure to specify the feed given to the dairy cows, and by Seidel et al. ${ }^{(43)}$, who neglected to detail the FA profile of the products and diets.
However, having said this, Seidel et al. ${ }^{(43)}$ had one of the most robust study designs, and showed some of the most interesting changes in blood cholesterol, in both NC and HC individuals. Furthermore, of the four studies that included milk as a test product, only Legrand et al. ${ }^{(45)}$ indicated whether the milk was full fat or not.

In addition to this lack of detailed study information, there was an evident, yet unexplainable, discrepancy between the FA profile of the modified products and the modified diets in many of these studies (see Table 4). The most notable example of such a discrepancy was Poppitt $e t a l .{ }^{(48)}$, where the PUFA content of the control and modified products was 3 and $10.5 \mathrm{~g} / 100 \mathrm{~g}$, respectively, whereas the PUFA content of the control and modified diets was 35 and $41 \mathrm{~g} / 100 \mathrm{~g}$, respectively. The study arms were matched for energy intake and all meals were provided, yet such a discrepancy would suggest that not all the dietary fat was substituted with the modified fat. Despite stating that the only dairy fat given to the volunteers was the control and modified butter, this only made up $50 \%$ of total dietary fat and thus the remaining $50 \%$ remains unaccounted for. It is thus apparent that a non-dairy fat source contributed a significant proportion of PUFA to the diets, which could have significantly made an impact on blood cholesterol changes.

Likewise, Noakes et $a l .{ }^{(41)}$ and Lacroix et $a l .{ }^{(47)}$ reported that the PUFA content of the control and modified products was 2 and $10 \mathrm{~g} / 100 \mathrm{~g}$ FA and 3.6 and $3.8 \mathrm{~g} / 100 \mathrm{~g}$, respectively, while that of the diet was 8.9 and $13.1 \mathrm{~g} / 100 \mathrm{~g}$ FA and 19.3 and $19.3 \mathrm{~g} / 100 \mathrm{~g}$, respectively (Table 4). Noakes et $a l .{ }^{(41)}$ restricted volunteers to a low-fat background diet of $15 \%$ energy from fat (with the remaining $20 \%$ energy from fat coming from the control and modified dairy products) and suggested consumption of foods of known fat content, in addition to provision of low-fat frozen meals. In contrast, Lacroix et al. ${ }^{(47)}$ focused on ensuring that the experimental butters were the sole source of R-TFA in the diets; the remaining fat in the diets was made up with various vegetable and animal oils (to maintain equal percentages of SFA, MUFA and PUFA in both diets). Thus while Noakes et al. ${ }^{(41)}$ sought to control for other fat sources, the background diet in the control group appeared to substantially increase their intake of PUFA during the study. Moreover, Lacroix et $a l .{ }^{(47)}$ designed the study to focus on the effect of R-TFA, eliminating any effect of a low-SFA, high-MUFA/ PUFA diet, thus rendering the difference in profiles between the product and the diet irrelevant.

Tholstrup et $a l .{ }^{(33,42)}$, Legrand et $a l .{ }^{(45)}$ and Weill et al. ${ }^{(46)}$ also showed large discrepancies between the FA profile of the products and the diets (Table 4). Yet contrary to the before-mentioned studies ${ }^{(41,47)}$, the FA information provided by these particular studies is incomplete and in some cases up to $33.9 \mathrm{~g} / 100 \mathrm{~g}$ FA are unidentified. Subsequently, drawing parallels between the FA profiles of the products and the diets becomes arbitrary. 
Nevertheless, despite considerable disparities between studies, there are some very similar trends in changes in blood cholesterol concentrations. As illustrated in Fig. 1, there is a noticeable downward trend in TC concentrations, as the percentage of energy from SFA decreases across all studies, except for NC individuals in the study of Seidel et $a l .{ }^{(43)}$. Critically, the increase in TC in these NC individuals is due to a substantial increase in HDL-C, rather than an increase in LDL-C (Table 3). In effect, Seidel et $a l^{(43)}$ (both $\mathrm{NC}$ and $\mathrm{HC}$ subjects) was the only study to show a significant increase in HDL-C. Reassuringly, there is a consistent downward trend across all studies for LDL-C, as percentage energy from SFA decreases (Fig. 1). In turn, Seidel et al. ${ }^{(43)}$ (both NC and HC subjects) was the only study to report a significant reduction in both the total:HDL and LDL:HDL ratios with a reduction of percentage energy from SFA. Interestingly, the slopes of these reductions in both $\mathrm{NC}$ and $\mathrm{HC}$ individuals are remarkably similar (Fig. 1). In contrast, both studies by Tholstrup et al. ${ }^{(33,42)}$ show a detrimental increase in both total:HDL-C and LDL-C:HDL-C ratios, due to Tholstrup et al. ${ }^{(42)}$ failing to show any significance changes in plasma cholesterol concentrations and Tholstrup et al. ${ }^{(33)}$ significantly reducing HDL-C.

Changes in cholesterol from four studies ${ }^{(44-47)}$ were not included in Fig. 1 due in part to one study having used only serum FA levels as markers of CVD risk ${ }^{(46)}$, but also due to the difference in study designs. Malpuech-Brugère et $a l .{ }^{(44)}$ and Legrand et al. ${ }^{(4)}$ both used parallel designs and, thus, using baseline cholesterol concentrations, these were reported as changes from baseline. However, while Legrand et al. ${ }^{(45)}$ provided both the significance of change between baseline and day 90 in the control and modified groups as well as between day 90 of the control and modified groups, Malpuech-Brugère et al. ${ }^{(44)}$ only reported the significance of 'estimate mean effects' (change between baseline and day 90) between the control and the modified group. Additionally, Lacroix et $a l .{ }^{(47)}$ employed a study design that aimed to focus solely on the effect of R-TFA on CVD risk markers. By matching the percentage of energy from SFA across both diets, it was not appropriate to include this study to look at the relationship between change in percentage energy from SFA and cholesterol.

The studies included in the present review were those that specifically tested the effects of milk and dairy products that had been modified through alteration of the cow's diet. As previously mentioned, an alternative approach for reducing SFA intake from milk and dairy products is the production of low-fat products by the skimming of milk fat. However, although studies testing the effects of these foods on CVD markers have shown some promise - as reviewed by Hooper et al. ${ }^{(24)}$ - altering the FA composition to increase proportions of potentially beneficial MUFA and PUFA would appear to offer the potential for greater health benefits to the consumer. Moreover, the palatability and texture of milk and dairy products rely heavily on their fat content, with consumer research indicating a preference for the mouthfeel of higher-fat dairy products compared with their low-fat alternatives ${ }^{(55)}$.

A further strategy for modifying milk fat content that was not covered in the present review is the addition of oils directly to the milk or dairy products to increase proportions of MUFA and PUFA without intervention at the farm level. Wood et al. ${ }^{(40)}$ demonstrated that by blending equal parts of butter with olive oil or sunflower-seed oil the ratio of SFA:MUFA:PUFA can be changed (butter, 57:32:11; butter-olive oil, 39:46:15; butter-sunflowerseed oil, 37:31:32); however, when fed to thirty-eight healthy men, these modified butters did not reduce serum lipid levels below baseline values. Although this approach is advantageous in its simplicity, manipulation of the dairy cow's diet not only leads to an altered milk FA composition, but may also beneficially affect ruminant health, milk yield ${ }^{(56)}$ and reduce methane emissions ${ }^{(57)}$.

\section{Summary of the evidence}

The present review has highlighted the heterogeneity of the limited number of studies investigating the association between the consumption of modified milk and dairy products and CVD risk. Of the eight studies that measured blood cholesterol, four reported a significant reduction in TC and LDL-C following chronic consumption of modified milk and dairy products for a period of $4-13$ weeks. Thus, the over-arching conclusion from these studies is that consumption of milk and dairy products, where SFA have been partially replaced with MUFA and PUFA, has a beneficial impact on CVD lipid risk markers, but further evidence is required before a clear conclusion can be drawn.

\section{Gaps in the evidence}

As discussed, the heterogeneity between these chronic intervention studies makes forming well-powered estimations of CVD risk difficult. The variations in study designs, test products and estimations of CVD risk between studies highlight a number of areas that require further investigation, notably the potentially contrasting effects of different milk and dairy products on CVD risk, as well as the strength of cardiovascular risk markers utilised.

\section{The milk and cheese paradox}

The role of milk in cardiovascular health has been the centre of much debate. Despite milk fat having a SFA content of $70-75 \%$, epidemiological evidence indicates that milk is potentially cardioprotective ${ }^{(58)}$. Elwood et al. ${ }^{(58)}$ conducted a meta-analysis of ten studies looking specifically at the effect of milk on CVD and calculated a pooled estimate of relative odds, relative to the risk in subjects with the lowest consumption, of 0.87 (95\% CI 
$0.74,1.03)$ for IHD, $0.83(95 \%$ CI $0.77,0.90)$ for ischaemic stroke and 0.84 (95\% CI 0.78, 0.90) for any vascular event. Although the information was not available for most studies, the authors suggest that the milk drunk was predominantly whole milk, with semi-skimmed milk only becoming available during the latter years of these studies.

Furthermore, the role of cheese consumption in CVD risk is of interest. There is limited information on epidemiological links between cheese consumption and CVD risk due to cheese often being grouped collectively with butter, which is thought to increase LDL-C and $\mathrm{TC}^{(59)}$. Nonetheless, two large studies identified no association between cheese consumption and CVD, while positively linking consumption of other dairy products ${ }^{(60,61)}$. Additional evidence from epidemiological and dietary intervention studies suggests that cheese has a neutral effect on plasma cholesterol $^{(62)}$, yet, importantly, highlights the type of cheese as an important variable for risk ${ }^{(63)}$. Moreover, a recent study by Hjerpsted et al. ${ }^{(64)}$ demonstrated that cheese lowers LDL-C when compared with butter intake of equal fat content.

The most plausible explanation proposed for the potentially protective role of milk and cheese is the presence of the cardioprotective agents such as $\mathrm{Ca}$ and bioactive milk peptides $^{(65)}$, which are low in other dairy products such as butter. While $\mathrm{Ca}$ is thought to reduce blood pressure by acting on parathyroid hormone ${ }^{(66)}$, milk peptides may be cardioprotective by inhibiting angiotensin-converting enzyme associated with the production of angiotensin II, a potent vasoconstrictor $^{(67)}$.

This epidemiological and intervention-based evidence in support of milk and cheese as potential protective agents for cardiovascular health does not adequately distinguish between individual dairy products, and studies investigating specific dairy products are limited. Milk and cheese were incorporated into four of the nine studies reviewed in the present article ${ }^{(41,43,45,46)}$; however, other dairy products, notably butter, were included and thus do not provide a clear picture of the role of milk and cheese compared with other dairy products. The complex nature of milk and cheese, coupled with their widespread consumption, warrants further investigation.

\section{Measure of CVD risk}

In addition to the gap in evidence surrounding the role of milk and cheese, a greater diversity of CVD risk markers is required to help elucidate the impact of modified dairy products on CVD. For over 60 years research has considered the use of plasma lipids - HDL-C, LDL-C, TC - as indicators of CVD risk ${ }^{(68,69)}$. However, including holistic measures of CVD such as blood pressure, inflammation and vascular function is especially important when evaluating the effect of milk and dairy products due to their counterbalancing effects on CVD risk.
Furthermore, the presence of inflammatory markers such as IL-6, C-reactive protein and TNF- $\alpha$ are additional markers of CVD risk due to their role in atherosclerotic lesion progression ${ }^{(70)}$. Although all studies in the present review, except for Noakes et al. ${ }^{(41)}$, investigated a number of these markers, no significant results were found. More research is needed to elucidate this area.

In addition to the use of blood pressure and inflammation as markers of CVD risk, the use of vascular reactivity techniques in research settings has been steadily increasing; such techniques include pulse wave velocity/analysis, laser Doppler imaging, digital volume pulse and the 'gold standard' flow-mediated dilatation. Evidence suggests a strong link between endothelial dysfunction and $\mathrm{CVD}^{(71)}$. One such study, by Halcox et $a l^{(72)}$, highlighted endothelial dysfunction as a predictor of CVD based on a longitudinal prospective study in 308 patients, where coronary vascular resistance and epicardial diameter were measured.

These techniques base their estimation of CVD risk on the responsiveness of the vascular endothelial cell wall to stimuli. When healthy, the endothelium is elastic and actively produces mediators, such as NO, that inhibit leucocyte adhesion, modulate smooth muscle proliferation and inhibit platelet aggregation ${ }^{(73)}$. However, when damaged by mediators of vascular dysfunction such as smoking ${ }^{(74)}$, diet $^{(10)}$ and obesity ${ }^{(75)}$, the endothelium becomes stiffer and less responsive to vasodilation stimuli, increasing the chance of cardiovascular-related diseases.

Importantly, a recent study has supported the use of measures of endothelial function (pulse wave velocity and pulse pressure) in assessing the role of dairy intake on CVD risk by showing a linear decrease in pulse wave velocity ( $P$ for trend $=0.018$ ) and pulse pressure ( $P$ for trend $=0.013)$ with increasing frequencies of dairy product intake $^{(76)}$. Therefore, based on emerging evidence, measurement of the responsiveness of the vascular endothelial cells, blood pressure measures and markers of inflammation may offer a more appropriate indicator of CVD risk than blood lipids alone.

\section{Conclusions}

Over 100 studies have investigated the impact of modifying the bovine diet to alter milk FA composition, notably to lower concentrations of SFA by substituting the diet with a source of MUFA or PUFA. However, few studies have assessed the effects of these modified products on CVD risk markers in a human intervention study. The studies presented in this review provided a high-UFA (MUFA, PUFA or mixed) feed supplement to the bovine diet to modify milk FA concentrations. However, the provision of a high-UFA diet to the cow leads to increased R-TFA in these test foods. While the atherogenic potential of these R-TFA is yet to be clarified, with many studies inadequately reporting R-TFA concentrations, the question of whether lowering SFA concentrations, with the corresponding 
increase in R-TFA concentrations, is beneficial to cardiovascular health is a poignant question.

While the majority of the studies evaluated in the present review showed a beneficial effect on at least one biomarker of CVD risk, the need for more convincing evidence is abundantly apparent. Specifically, insufficient evidence exists for dairy products other than butter and their relationship with CVD risk, most notably milk and cheese, which may be cardioprotective. Moreover, all studies to date have measured plasma lipid markers as their primary measure of CVD risk. In order to evaluate a more complete picture of CVD risk, determination of other risk factors such as blood pressure and inflammatory markers, as well as novel, vascular endothelium-based measures of risk, would seem prudent.

\section{Acknowledgements}

The present review was supported by the Barham Benevolent Trust and the University of Reading. All authors contributed to, and approved, the final version of the manuscript. There are no conflicts of interest.

\section{References}

1. Siri-Tarino PW, Sun Q, Hu FB, et al. (2010) Saturated fat, carbohydrate, and cardiovascular disease. Am J Clin Nutr 91, 502-509.

2. Givens DI, Kliem KE, Humphries DJ, et al. (2009) Effect of replacing calcium salts of palm oil distillate with rapeseed oil, milled or whole rapeseeds on milk fatty-acid composition in cows fed maize silage-based diets. Animal 3, 1067-1074.

3. Allender S, Scarborough P \& Peto V, et al. (2008) European cardiovascular disease statistics 2008. http://www.ehnheart. org/cvd-statistics.html (accessed December 2011).

4. British Heart Foundation (2010) Coronary heart disease statistics 2010. http://www.bhf.org.uk/publications/view-publica tion.aspx?ps=10,01546 (accessed December 2011).

5. Stephen AM \& Sieber GM (1994) Trends in individual fat consumption in the UK 1900-1985. Br J Nutr 71, 775-788.

6. Henderson L, Gregory J, Irving K, et al. (2003) Energy, Protein, Carbohydrate, Fat and Alcohol Intake. Vol. 2: The National Diet and Nutrition Survey: Adults Aged 19 to 64 Years. London: The Stationery Office.

7. Department of Health (2011) National Diet and Nutrition Survey. Headline results from years 1 and 2 (combined) of the rolling programme 2008/9-2009/10. http://www.dh.gov.uk/en/ Publicationsandstatistics/Publications/PublicationsStatistics/ DH_12,8166 (accessed November 2011).

8. Hunter JE, Zhang J \& Kris-Etherton PM (2010) Cardiovascular disease risk of dietary stearic acid compared with trans, other saturated, and unsaturated fatty acids: a systematic review. Am J Clin Nutr 91, 46-63.

9. Mensink RP, Zock PL, Kester ADM, et al. (2003) Effects of dietary fatty acids and carbohydrates on the ratio of serum total to HDL cholesterol and on serum lipids and apolipoproteins: a meta-analysis of 60 controlled trials. Am J Clin Nutr 77, 1146-1155.

10. Nicholls SJ, Lundman P, Harmer JA, et al. (2006) Consumption of saturated fat impairs the anti-inflammatory properties of high-density lipoproteins and endothelial function. $J \mathrm{Am}$ Coll Cardiol 48, 715-720.
11. Keogh JB, Grieger JA, Noakes M, et al. (2005) Flow-mediated dilatation is impaired by a high-saturated fat diet but not by a high-carbohydrate diet. Arterioscler Thromb Vasc Biol 25, 1274-1279.

12. Blumenthal JA, Babyak MA, Hinderliter A, et al. (2010) Effects of the DASH diet alone and in combination with exercise and weight loss on blood pressure and cardiovascular biomarkers in men and women with high blood pressure: the ENCORE Study. Arch Intern Med 170, 126-135.

13. Tierney AC, McMonagle J, Shaw DI, et al. (2011) Effects of dietary fat modification on insulin sensitivity and on other risk factors of the metabolic syndrome - LIPGENE: a European randomized dietary intervention study. Int $J$ Obes 35, 800-809.

14. Jebb SA, Lovegrove JA, Griffin BA, et al. (2010) Effect of changing the amount and type of fat and carbohydrate on insulin sensitivity and cardiovascular risk: the RISCK (Reading, Imperial, Surrey, Cambridge, and Kings) trial. Am J Clin Nutr 92, 748-758.

15. United States Department of Agriculture (2011) USDA Nutrient Database for Standard Reference, Release $24 \mathrm{http}: / / \mathrm{ndb}$. nal.usda.gov/ndb/foods/list (accessed January 2012).

16. Månsson HL (2008) Fatty acids in bovine milk fat. Food Nutr Res 52 (epublication 11 June 2008)

17. Hulshof KF, van Erp-Baart MA, Anttolainen M, et al. (1999) Intake of fatty acids in Western Europe with emphasis on trans fatty acids: the TRANSFAIR study. Eur J Clin Nutr $\mathbf{5 3}$, $143-157$.

18. Milk Development Council (2012) Dairy consumption. http://www.dairyco.org.uk/ (accessed January 2012).

19. Elwood PC, Pickering JE, Givens ID, et al. (2010) The consumption of milk and dairy foods and the incidence of vascular disease and diabetes: an overview of the evidence. Lipids 45, 925-939.

20. McCarron DA \& Reusser ME (1999) Finding consensus in the dietary calcium-blood pressure debate. J Am Coll Nutr 18, 398S-405S.

21. Sacks FM, Willett WC, Smith A, et al. (1998) Effect on blood pressure of potassium, calcium, and magnesium in women with low habitual intake. Hypertension 31, 131-138.

22. FitzGerald RJ, Murray BA \& Walsh DJ (2004) Hypotensive peptides from milk proteins. J Nutr 134, 980S-988S.

23. Dilzer A \& Park Y (2012) Implication of conjugated linoleic acid (CLA) in human health. Crit Rev Food Sci Nutr 52, $488-513$.

24. Hooper L, Summerbell CD, Thompson RL, et al. (2011) Effects of reducing or modifying dietary fat on CVD: a systematic review and meta-analysis of randomised controlled trials. Proc Nutr Soc 70, E222.

25. Mozaffarian D \& Wu JHY (2011) Omega-3 fatty acids and cardiovascular disease: effects on risk factors, molecular pathways, and clinical events. J Am Coll Cardiol 58, 2047-2067.

26. Mozaffarian D, Micha R \& Wallace S (2010) Effects on coronary heart disease of increasing polyunsaturated fat in place of saturated fat: a systematic review and meta-analysis of randomized controlled trials. PLos Med 7, e10,00252.

27. Astrup A, Dyerberg J, Elwood P, et al. (2011) The role of reducing intakes of saturated fat in the prevention of cardiovascular disease: where does the evidence stand in 2010? Am J Clin Nutr 93, 684-688.

28. Lloyd-Williams F, O'Flaherty M, Mwatsama M, et al. (2008) Estimating the cardiovascular mortality burden attributable to the European Common Agricultural Policy on dietary saturated fats. Bull World Health Organ 86, 535-541.

29. Glasser F, Ferlay A \& Chilliard Y (2008) Oilseed lipid supplements and fatty acid composition of cow milk: a meta-analysis. J Dairy Sci 91, 4687-4703. 
30. Milk Development Council (2012) Ruminant Physiology. http://www.dairyco.org.uk/farming-info-centre/feeding/plan ning-your-nutrition/ruminant-physiology.aspx (accessed January 2012).

31. Harfoot CG \& Hazlewood GP (1988) Lipid metabolism in the rumen. In The Rumen Microbial Ecosystem, pp. 285-322 [PN Hobson, editor]. New York: Elsevier Science Publishing.

32. Shingfield KJ, Bernard L, Leroux C, et al. (2010) Role of trans fatty acids in the nutritional regulation of mammary lipogenesis in ruminants. Animal 4, 1140-1166.

33. Tholstrup T, Raff M, Basu S, et al. (2006) Effects of butter high in ruminant trans and monounsaturated fatty acids on lipoproteins, incorporation of fatty acids into lipid classes, plasma C-reactive protein, oxidative stress, hemostatic variables, and insulin in healthy young men. Am J Clin Nutr 83, 237-243.

34. Mozaffarian D, Katan MB, Ascherio A, et al. (2006) Trans fatty acids and cardiovascular disease. $N$ Engl J Med 354, 1601-1613.

35. Jakobsen MU, Overvad K, Dyerberg J, et al. (2008) Intake of ruminant trans fatty acids and risk of coronary heart disease. Int J Epidemiol 37, 173-182.

36. Mozaffarian D, Cao H, King IB, et al. (2010) Trans-palmitoleic acid, metabolic risk factors, and new-onset diabetes in U.S. adults. Ann Intern Med 153, 790-799.

37. Bendsen NT, Christensen R, Bartels EM, et al. (2011) Consumption of industrial and ruminant trans fatty acids and risk of coronary heart disease: a systematic review and metaanalysis of cohort studies. Eur J Clin Nutr 65, 773-783.

38. Department of Health (1991) Dietary Reference Values for Food Energy and Nutrients for the United Kingdom. Vol. 41: Report on Health and Social Subjects. London: Her Majesty's Stationery Office.

39. Fonollá J, López-Huertas E, Machado FJ, et al. (2009) Milk enriched with 'healthy fatty acids' improves cardiovascular risk markers and nutritional status in human volunteers. Nutrition 25, 408-414.

40. Wood R, Kubena K, O’Brien B, et al. (1993) Effect of butter, mono- and polyunsaturated fatty acid-enriched butter, trans fatty acid margarine, and zero trans fatty acid margarine on serum lipids and lipoproteins in healthy men. J Lipid Res $\mathbf{3 4}$, 1-11.

41. Noakes M, Nestel P \& Clifton P (1996) Modifying the fatty acid profile of dairy products through feedlot technology lowers plasma cholesterol of humans consuming the products. Am J Clin Nutr 63, 42-46.

42. Tholstrup T, Sandstrom B, Hermansen JE, et al. (1998) Effect of modified dairy fat on postprandial and fasting plasma lipids and lipoproteins in healthy young men. Lipids 33, 11-21.

43. Seidel C, Deufel T \& Jahreis G (2005) Effects of fat-modified dairy products on blood lipids in humans in comparison with other fats. Ann Nutr Metab 49, 42-48.

44. Malpuech-Brugère C, Mouriot J, Boue-Vaysse C, et al. (2010) Differential impact of milk fatty acid profiles on cardiovascular risk biomarkers in healthy men and women. Eur J Clin Nutr 64, 752-759.

45. Legrand P, Schmitt B, Mourot J, et al. (2010) The consumption of food products from linseed-fed animals maintains erythrocyte omega-3 fatty acids in obese humans. Lipids 45, 11-19.

46. Weill P, Schmitt B, Chesneau G, et al. (2002) Effects of introducing linseed in livestock diet on blood fatty acid composition of consumers of animal products. Ann Nutr Metab 46, $182-191$.

47. Lacroix É, Charest A, Cyr A, et al. (2012) Randomized controlled study of the effect of a butter naturally enriched in trans fatty acids on blood lipids in healthy women. $\mathrm{Am}$ J Clin Nutr 95, 318-325.

48. Poppitt SD, Keogh GF, Mulvey TB, et al. (2002) Lipid-lowering effects of a modified butter fat: a controlled intervention trial. Eur J Clin Nutr 56, 64-71.

49. Cholesterol Treatment Trialists' Collaborators (2005) Efficacy and safety of cholesterol-lowering treatment: prospective meta-analysis of data from 90,056 participants in 14 randomised trials of statins. Lancet 366, 1267-1278.

50. Margo AD \& Ivan DF (1993) Response to a cholesterollowering diet: efficacy is greater in hypercholesterolemic subjects even after adjustment for regression to the mean. Am J Med 94, 626-631.

51. Shingfield KJ, Ahvenjärvi S, Toivonen V, et al. (2003) Effect of dietary fish oil on biohydrogenation of fatty acids and milk fatty acid content in cows. Anim Sci 77, 165-179.

52. Wang L, Folsom AR, Eckfeldt JH, et al. (2003) Plasma fatty acid composition and incidence of coronary heart disease in middle aged adults: The Atherosclerosis Risk in Communities (ARIC) Study. Nutr Metab Cardiovasc Dis 13, 256-266.

53. Burdge GC (2006) Metabolism of $\alpha$-linolenic acid in humans. Prostaglandins Leukot Essent Fatty Acids 75, 161-168.

54. Lock AL \& Shingfield KJ (2004) Optimising milk composition. In Dairying: Using Science to Meet Consumers Needs, pp. 107-188 [E Kebreab, J Mills and DE Beever, editors]. Nottingham: Nottingham University Press.

55. Hamilton J, Knox B, Hill D, et al. (2000) Reduced fat products - consumer perceptions and preferences. Br Food $J$ 102, 494-506.

56. Bork NR, Schroeder JW, Lardy GP, et al. (2010) Effect of feeding rolled flaxseed on milk fatty acid profiles and reproductive performance of dairy cows. J Anim Sci 88, 3739-3748.

57. Chilliard Y, Martin C, Rouel J, et al. (2009) Milk fatty acids in dairy cows fed whole crude linseed, extruded linseed, or linseed oil, and their relationship with methane output. J Dairy Sci 92, 5199-5211.

58. Elwood PC, Pickering JE, Hughes J, et al. (2004) Milk drinking, ischaemic heart disease and ischaemic stroke II. Evidence from cohort studies. Eur J Clin Nutr 58, 718-724.

59. Denke MA, Adams-Huet B \& Nguyen AT (2000) Individual cholesterol variation in response to a margarine- or butterbased diet. J Am Med Assoc 284, 2740-2747.

60. Artaud-Wild S, Connor S, Sexton G, et al. (1993) Differences in coronary mortality can be explained by differences in cholesterol and saturated fat intake in 40 countries, but not in France and Finland. Circulation 88, 2771-2779.

61. Renaud S \& de Lorgeril M (1989) Dietary lipids and their relation to ischaemic heart disease: from epidemiology to prevention. J Intern Med 225, 39-46.

62. Tholstrup T (2006) Dairy products and cardiovascular disease. Curr Opin Lipidol 17, 1-10.

63. Houston DK, Driver KE, Bush AJ, et al. (2008) The association between cheese consumption and cardiovascular risk factors among adults. J Hum Nutr Diet 21, 129-140.

64. Hjerpsted J, Leedo E \& Tholstrup T (2011) Cheese intake in large amounts lowers LDL-cholesterol concentrations compared with butter intake of equal fat content. Am J Clin Nutr 94, 1479-1484.

65. Kamau SM, Lu R-R, Chen W, et al. (2010) Functional significance of bioactive peptides derived from milk proteins. Food Rev Int 26, 386-401.

66. Allender PS, Cutler JA, Follmann D, et al. (1996) Dietary calcium and blood pressure. Ann Intern Med 124, 825-831.

67. Jauhiainen T \& Korpela R (2007) Milk peptides and blood pressure. J Nutr 137, 825S-829S. 
68. Hegsted DM, McGandy RB, Myers ML, et al. (1965) Quantitative effects of dietary fat on serum cholesterol in man. Am J Clin Nutr 17, 281-295.

69. Moreton JR (1947) Atherosclerosis and alimentary hyperlipemia. Science 106, 190-191.

70. Tedgui A \& Mallat Z (2006) Cytokines in atherosclerosis: pathogenic and regulatory pathways. Physiol Rev 86, 515-581.

71. Triggle CR, Hollenberg M, Anderson TJ, et al. (2003) The endothelium in health and disease - a target for therapeutic intervention. J Smooth Muscle Res 39, 249-267.

72. Halcox JPJ, Schenke WH, Zalos G, et al. (2002) Prognostic value of coronary vascular endothelial dysfunction. Circulation 106, 653-658.

73. Kharbanda RK \& Deanfield JE (2001) Functions of the healthy endothelium. Coron Artery Dis 12, 485-491.

74. Celermajer DS, Adams MR, Clarkson P, et al. (1996) Passive smoking and impaired endothelium-dependent arterial dilatation in healthy young adults. $N$ Engl I Med 334, $150-155$.

75. Jonk AM, Houben AJHM, de Jongh RT, et al. (2007) Microvascular dysfunction in obesity: a potential mechanism in the pathogenesis of obesity-associated insulin resistance and hypertension. Physiology 22, 252-260.

76. Crichton GE, Elias MF, Dore GA, et al. (2012) Relations between dairy food intake and arterial stiffness. Hypertension 59, 1044-1051.

77. World Health Organization (2008) Interim summary of conclusions and dietary recommendations on total fat and fatty acids. http://www.who.int/nutrition/topics/FFA_summary_ rec_conclusion.pdf (accessed December 2011).

78. American Heart Association (2012) Know your fats. http:// www.heart.org/HEARTORG/Conditions/Cholesterol/Pre ventionTreatmentofHighCholesterol/Know-Your-Fats_UCM_ 30,5628_Article.jsp.Txg3JYG0Mup (accessed December 2011). 